\title{
Ron Mueck y la ilusión traumática de lo que está en falta
}

\section{Ron Mueck and the traumatic illusion of what is missing}

\author{
Israel García Plata ${ }^{a}$
}

\begin{abstract}
:
The following essay aims to offer an approach from aesthetics and art theory to the experience of hyperrealism in sculpture. We are particularly interested in this series of reflections hyperrealism in the sculpture of Australian artist Ron Mueck. The ideas that we have used involve the appreciations of Hal Foster, Ana María Guasch and Craig Raine. It is from these authors that we approach the experience of hyperrealism sculpture as a unique aesthetic experience in which an operation takes place that sets the viewer in front of an emptying of symbolic character, confronting him with unbeatable appearance of the perceived sculpture, and becoming, therefore, in a traumatic illusion of something that is missing.
\end{abstract}

Keywords:

Hyperrealism, sculpture, Ron Mueck, traumatic illusion, emptying

Resumen:

El siguiente ensayo tiene por objetivo ofrecer un acercamiento desde la estética y la teoría del arte a la experiencia del hiperrealismo en la escultura. Nos interesa particularmente en esta serie de reflexiones el hiperrealismo en la escultura del artista australiano Ron Mueck. Las ideas de las que nos hemos valido involucran las apreciaciones de Hal Foster, Ana María Guasch y Craig Raine. Es a partir de estos autores que abordamos la experiencia de la escultura hiperrealista como una singular experiencia estética en la que tiene lugar una operación que coloca al espectador frente a un vaciamiento de carácter simbólico, confrontándole con la apariencia insoslayable de la escultura percibida, y aconteciendo, por tanto, una ilusión traumática de algo que está en falta.

Palabras Clave:

Hiperrealismo, escultura, Ron Mueck, ilusión traumática, vaciamiento

\section{Introducción}

Una de las principales características del arte

contemporáneo es el empleo de nuevos materiales en la producción de la obra, concretamente en el ámbito de la escultura. Como resultado del impulso por la vanguardia y el eclecticismo predominante en nuestra época, la composición material de las obras de arte se ha visto potenciada en función de nuevas texturas como la fibra de vidrio, la resina epoxi, el acrílico, el silicón, entre otros tantos materiales que han ofrecido una gama muchísimo más amplia de posibilidades para conseguir los efectos deseados por el artista en función de la maleabilidad y el resultado de las texturas de esos materiales. Estos materiales de alta tecnología que fueron pensados originalmente para la creación de objetos para el consumo, se traducen en la actividad artística como posibilidades para efectos de la ilusión, tanto fantástica como realista. De hecho, la aplicación de nuevos materiales en el campo del arte constituye uno de los paradigmas que dividen el modernismo y el postmodernismo artístico. El teórico norteamericano Hal 
Foster hace referencia a ello en tanto que un grupo de artistas partidarios de "la defensa del signo" en contra de la tendencia reductiva del minimalismo, comenzaron a experimentar en los años sesentas y setentas con nuevos materiales y nuevas técnicas en la composición de su obra, periodo que corresponde a la tardomodernidad y evidentemente, a los inicios de la posmodernidad.

\begin{abstract}
"Algunos artistas trataron de resistirse a la disolución del signo, fundamentarlo por otras vías: primero con nuevos materiales y técnicas (evidente en el minimalismo, este fetichismo se hizo dominante en los experimentos posminimalistas en proceso)" (Foster, 2001, p. 82).
\end{abstract}

Es así pues que el arte contemporáneo, del que propiamente podemos decir que comienza en la década de los sesentas como una resistencia en cuanto ésta constituye también una crítica a las instituciones del arte, a la concepción greenbergiana del arte puro y formalista exclusivo a los límites del abstraccionismo, una crítica a las lógicas del capitalismo y la consecuente reducción de la obra en objeto-mercancía para el consumo, así también esa resistencia es una afrenta de cierto tipo de arte posmoderno que se opone a la disolución del signo en la obra de arte como ya amenazaba el minimalismo, y razón por la que se hace uso de nuevos técnicas y materiales. El empleo de estas nuevas técnicas y nuevos materiales en la pintura, pero sobre todo en la escultura, responde también y de manera más inmediata, a las posibilidades mismas que ofrece la naturaleza de dichos materiales y que los artistas de la época no tardaron en descubrir y hacer intervenir en su trabajo. Con la llegada de las resinas, acrílicos y demás polímeros sintéticos, el artista encontró nuevas formas de resistencia crítica pero también creativa. Fue así que la escultura al hacer uso de estos materiales resultantes de la práctica tecnológica, se encontró con una renovación tal que le significó un nuevo auge en cuanto a su lugar en las llamadas bellas artes.

\section{Desarrollo}

El realismo escultórico que deriva de la implementación de nuevas técnicas y nuevos materiales en la composición posmoderna logró dirigir su principal interés hacia la percepción de la obra de arte escultórica en las texturas, en oposición a la autoridad de las formas. Esto es, en el realismo escultórico moderno que ostentaba su valor en la proporción y el tratado de las figuras, en la mímesis casi absoluta de las partes como en aquellas esculturas del Renacimiento y posteriormente del Barroco y el Neoclásico, parece ahora orientar su realismo no sólo en la perfección de las formas de las que se ocupa sino, sobre todo, en las texturas que recubren a esas formas realistas. El resultado de ello es precisamente un hiperrealismo que surge en los años sesentas y se consolida en los años setentas en Europa y que se caracteriza por hacer surgir una particular ilusión realista de orden superior. 
"[N]o fue sino hasta 1972 cuando las tendencias fotorrealistas, que empezaban a difundirse en Europa con el nombre de hiperrealismo y que en Estados Unidos eran conocidas también con las expresiones Sharp Realism, Superrealism y Radical Realism.” (Guasch, 2002, p.201).

La orientación que toma la escultura hiperrealista es el resultado de una sobreexposición de elementos al espectador, en donde el elemento de la textura cobra un papel determinante en el realismo resultante de estas prácticas postmodernas. Es innegable así el realismo de las esculturas de Miguel Ángel o de las esculturas de Bernini, sin embargo su valor radica enteramente en la forma armónica como patrón de la belleza, en el uso del mármol como material emblemático para representar formas bellas. Sin embargo, ese realismo no se elevaba hasta el nivel de un desconcierto radical en donde uno no sabe si realmente lo que tenemos delante se trata de una escultura o de "algo real". La ilusión mimética del hiperrealismo alcanza entonces un nivel de cuestionamiento incluso sobre los mecanismos de percepción. Esa distinción entre el realismo moderno y el realismo postmoderno que se vale de materiales sintéticos, se entiende también precisamente por el viraje a la textura y su tratamiento casi obsesivo de cada parte de la composición escultórica.

Uno de los escultores contemporáneos más representativos del hiperrealismo de los últimos años es el australiano Ron Mueck. Su obra compuesta por una serie de esculturas increíblemente realistas, y por ello, enteramente impactantes y sorprendentes para el espectador, está llamando la atención de la crítica mundial especializada. Revistas de divulgación internacional especializadas en crítica de arte como ArtPress y Sculpture (Cfr. ArtPress en las ediciones número 288 y 317, y en Sculpture en la edición de julio/agosto 2003, Vol. 22, Núm. 6) le han dedicado tanto entrevistas como críticas. La aparición de Ron Mueck en la escena mundial del arte se dio en el marco de una exposición de organizada por el renombrado empresario y coleccionista de arte Charles Saatchi. La muestra Sensation: Young British Artists From the Saatchi Collection, realizada en Londres en el año 1997 en la Royal Academy of London, en donde junto a Damien Hirst, Jake and Dinos Chapman y Jenny Saville, entre otros, Ron Mueck expone su obra titulada Dead Dad, obra que causó interés por el extremo realismo de su escultura.

A propósito de dicha exposición, el crítico inglés Craig Raine, publica en un artículo para el periódico también inglés The Guardian:

"Among this clamorous, attention-seeking art there is good work - by Jenny Saville, Rachel Whiteread, and the photographer Richard Billingham. And there, on the floor, 3ft long, is one indisputable, obvious masterpiece - a single work, the understated Dead Dad by Ron Mueck, the Australian son-in-law of Paula Rego - a calmly brilliant sculpture which is the contemporary equivalent of, say, Holbein's subtle 
portrait of Erasmus, with its engaged intelligence and wryly amused thin mouth." (Raine, 2006).

Craig Raine también describe lo que observa en Dead Dad:

\begin{abstract}
"The greatness of Dead Dad is oxymoronic: it's very completeness also tells us something is missing. The sculpture dispassionately records every delicate and indelicate bodily detail - detail that is alive with accuracy. Nothing is missing. Tendons, toenails, the direction of dark hair on the calves, the hazy pubes a little stationary mirage, the tidy greying hair, the polished, modest, uncircumcised cosh of the penis at four o'clock, which echoes the thumbs across the open, upturned palms." (Raine, 2006)
\end{abstract}

Lo que llama la atención de estas observaciones al respecto de la escultura de Mueck, es aquello que Craig afirma "está en falta", es decir, hay en la obra todo en cuanto se pueda pedir para una ilusión casi perfecta, sin embargo, algo no aparece. Para Craig, aquello que no está es el "sentimentalismo", incluso tratándose de la escultura del propio padre de Mueck que yace desnudo sobre una superficie. Esa falta de "sentimentalismo" tan presente en la escultura de Mueck, esa impotencia de lograr una cierta clase de empatía con su obra puesto que más bien nos ofrece un hieratismo total, supone un realismo o una ilusión de realidad muda que está muy presente en todo el trabajo escultórico de artista australiano. Esa característica de su trabajo se comprende plenamente desde la "frialdad" particular de todo hiperrealismo; sin embargo, en la obra de Mueck parece alcanzarse un punto álgido de realismo extremo que presupone una ilusión desoladora y traumática.

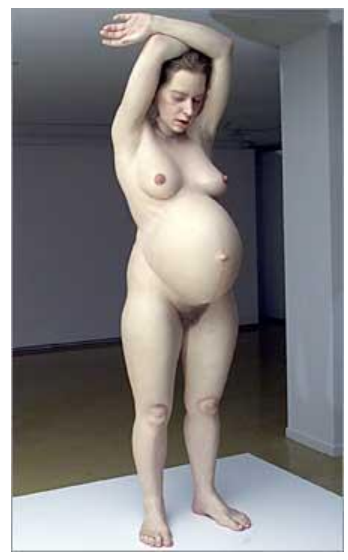

Figure 1. Mueck, Ron. Pregnant woman, 2002. Fibra de vidrio, resina, silicon. $252.0 \mathrm{~h} \times 78.0 \mathrm{w} \times 72.0 \mathrm{~d} \mathrm{~cm}$. Galería Nacional de Australia.

El acercamiento de Mueck al arte evidencia un fenómeno curioso en las prácticas artísticas contemporáneas. Mueck no es un artista de formación, no es escultor de academia y su vínculo con el arte se dio de manera indirecta. Él desde muy pequeño trabajó con sus padres quienes eran fabricantes de juguetes. Años más tarde, Mueck se encontraba colaborando en un programa de televisión australiano diseñando y creando personajes para dicho programa y colaborando de igual manera en los efectos especiales de una película australiana para niños. Posteriormente, una vez habiéndose mudado a Londres, comenzó a trabajar de manera independiente ofreciendo su trabajo para la industria de la publicidad. Fue en Londres donde, a través de su suegra la pintora de origen portugués nacionalizada inglesa Paula Rego, Mueck conoce a Saatchi y éste se 
interesa por su trabajo, encargándole entonces una serie de esculturas para sumarlas a su colección.

La obra de Ron Mueck debe situarse en una línea escultórica que viene del hiperrealismo norteamericano como una derivación del arte pop en su expresión más fría. Ana María Guasch sostiene que el hiperrealismo tiene su origen en una crítica al modelo formalista de Greenberg y al minimalismo predominante, que como también sostiene Foster, amenazaba con disolver el signo en la obra de arte.

"La principal aportación de A. Katz y Ph. Pearlstein al reconocimiento del realismo fue su lucha contra los movimientos de la abstracción pospictórica y del minimalismo y, principalmente, contra el reduccionismo extremo del pensamiento formalista greenbergiano, que a partir del Pop Art había tachado de reaccionario y conformista a todo arte realista $y$, en comparación con el abstracto, de falto de originalidad." (Guasch, 2002, p. 199).

El hiperrealismo desde su origen busca entonces dirigirse a aquello que se opone a la abstracción tan defendida por Greenberg, al arte conceptual que subordina a su objeto del cual es expresión; por tanto, el hiperrealismo busca la ilusión de la realidad más extrema, busca apelar a lo real pero desde la apariencia misma y no desde su trasfondo filosófico o espiritual. Pero lo que consigue el hiperrealismo con ello es mostrar al espectador la apariencia en bruto, la apariencia en estado salvaje, desprovista de todo contenido sentimental. Lo que está en falta desde los orígenes del hiperrealismo es el "sentimentalismo" como sostiene Craig, o el "Alma" que literalmente anima los cuerpos. La etimología del término Alma según es entendida por la tradición judeo-cristiana, es la que refiere a "aquello que otorga movimiento", aquello que "mueve desde dentro". Lo que hizo entonces el hiperrealismo en la década de los sesentas en el ámbito de la pintura -concretamente en el año 1968 para Guasch-y más tarde en la escultura hiperrealista, es que al ofrecer al espectador una ilusión casi perfecta de la apariencia de los objetos y los cuerpos, el hiperrealismo evidenció la ausencia del "elemento anímico" de los cuerpos representados en la escultura, aniquiló todo contenido sentimental de la obra en aras de la objetividad absoluta en el tratamiento de la apariencia, y con ello, anuló la dimensión subjetiva en la representación artística, logrando así un desconcierto tal en el espectador que se asume la contemplación de la escultura hiperrealista desde una experiencia silenciosa de choque. Al observar una escultura hiperrealista de Mueck, por ejemplo, quien al valerse de materiales y texturas que asemejan casi milimétricamente cada detalle de aquello que representa, el artista pareciera hacer irrumpir al espectador en la intimidad de los personajes representados, como si los hombres y mujeres representados en su escultura no fueran objetos artísticos, "obras" strictu sensu, sino una suerte de verdaderos cuerpos vacíos, desprovistos de alma. Las esculturas de Mueck se miran en completo silencio, la casi perfecta ilusión realista de su trabajo genera en el espectador una sensación de sorpresa tal que la 
dirección de nuestra conciencia yace exclusivamente en el ojo, en el puro acto de observar.

Para Hal Foster, el hiperrealismo intenta, más que representar lo real, "sellarlo". El hiperrealismo no es que busque representar lo real expresándolo, sino por el contrario, su intención es la de "embalsamarlo de apariencias".

“[E]l hiperrealismo es más que un engaño del ojo. Es un subterfugio contra lo real, un arte empeñado no sólo en pacificar lo real sino en sellarlo tras las superficies, en embalsamado en apariencias." (Foster, 2001, p. 145).

Lo real estaría pues según la idea de Foster, recubierto de apariencias, lo real sufriría entonces una suerte de momificación. De cualquier modo, en el hiperrealismo parece testimoniarse algo que no está, algo que sigue en falta, y eso, es lo real que no aparece de ningún modo, ni como proceso empático con el espectador desde una cierta conexión sentimental muy frecuente en la mayoría de las manifestaciones artísticas, ni lo real como profundidad representacional que sí pretende expresar, por ejemplo, el surrealismo. El hiperrealismo disfraza de apariencias aquello que se entiende como lo real, como la dimensión profunda de las representaciones y de la subjetividad. Dice el mismo Foster:

“El hiperrealismo también tiene que ver con esto real que está debajo, pero en cuanto hiperrealismo intenta mantenerse por encima de esto, mantenerlo abajo. A diferencia del surrealismo, pues, quiere ocultar más que revelar esto real; por eso extiende sus capas de signos y superficies extraídos del mundo de los bienes de consumo no sólo contra la profundidad representacional, sino también contra lo real traumático." (Foster, 2001, p. 148).

El hiperrealismo sería para Foster un ejercicio de silencio, de acallamiento sobre lo real que es una dimensión profunda y posiblemente oscura, traumática. El interior como elemento ausente en toda escultura por el hecho mismo de tratarse de una representación artificiosa, pero que en la ilusión de realidad extrema del hiperrealismo esta ausencia se vuelve incluso patética porque uno entra en cuenta de que sólo eso, lo que se entiende por alma y por lo real en sí mismo, es sencillamente irrepresentable, por lo que en la escultura hiperrealista se agudizaría el hecho de mirar lo que aparentemente es un sujeto pues así lo afirman los ojos

\section{Conclusión}

Quien sufre este llamado “ilusionismo traumático" es evidentemente el espectador que se enfrenta a una apariencia bruta, a una percepción del otro que es idéntico a uno mismo pero que "no le responde", que permanece mudo como el Moisés a Miguel Ángel. Entrar a una sala donde se expone escultura hiperrealista y en particular la de Mueck, nos da la impresión extraña y 
desconcertante de que nos encontramos irrumpiendo en un recinto privado, como si el espectador invadiese la habitación del personaje expuesto, como si violáramos su intimidad; sin embargo, la impresión dura poco, en breve nos reponemos de la apariencia hiperrealista, y recordamos que lo que nuestros ojos nos dicen que es verdad, en realidad no se trata más que de una ilusión, no obstante dicha experiencia constituye una experiencia de choque característica del arte contemporáneo.

La escultura de Ron Mueck se entiende entonces desde esas primeras manifestaciones hiperrealistas que aparecieron en la década de los sesentas en el campo de la pintura principalmente y posteriormente en la escultura. Concretamente es a partir de los trabajos escultóricos de John de Andrea y Duane Hanson, en donde la singularidad de las técnicas y el realismo de las texturas y las formas de las esculturas de Ron Mueck adquieren toda su importancia. Ana María Guasch refiere al trabajo de estos dos artistas que anteceden la obra de Mueck y alude también a la entonces novedosa aplicación de esas técnicas y materiales que dieron un giro a la escultura postmoderna:

"[John de Andrea] trabaja a partir de los propios moldes -réplicas perfectas de hombres y mujeres en poliéster y fibra de vidrio- para conseguir una especie de catálogo-inventario de personajes solitarios o en grupo, vestidos 0 desnudos. (...) [Duane Hanson] partió también de vaciados de cuerpos humanos resueltos en resina de poliéster y fibra de vidrio que pintaba, vestía y calzaba distanciándose del modelo original para crear arquetipos de su entorno social: jubilados, turistas, vigilantes de museo, amas de casa, deportistas, etc. Aunque en sus fotografías tridimensionales D. Hanson retrató, por lo común con mirada aséptica e irónica, la banalidad, la vulgaridad y el tedio dominantes en un determinado sector de la sociedad norteamericana, en ocasiones se acercó con sentido crítico a ciertos acontecimientos sociopolíticos. (...) (Guasch, 2002, p. 210).

Lo que resulta interesante es el resultado que consiguen estos artistas a partir del tratamiento novedoso de sus objetos artísticos. Dice Guasch que con de Andrea vemos réplicas perfectas de "personajes solitarios", mientras que con Hanson, personajes de la vida cotidiana, sesgados por esa "cotidianidad" que les arranca cualquier individualidad pues nos muestra "arquetipos" de personajes comunes a las sociedades de consumo, personajes típicos del llamado american way of life. El resultado es pues esa "fría sensibilidad" que caracteriza al hiperrealismo en sus orígenes y que en Ron Mueck se eleva hasta la muda contemplación producto de la sorpresa y el efecto de choque. 


\section{Referencias}

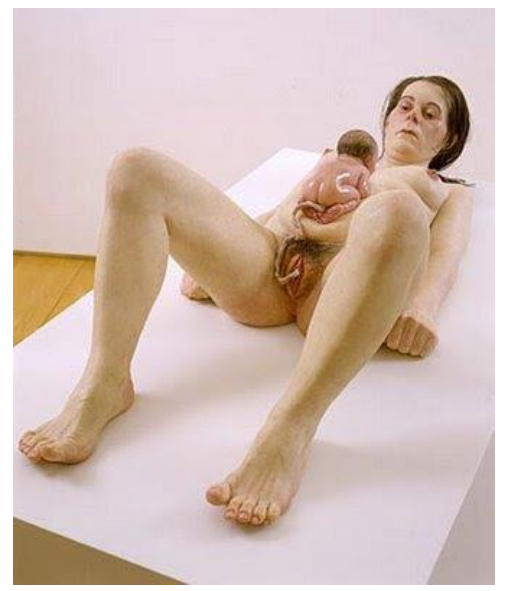

[1] Foster, H. (2001): El retorno de lo real. La vanguardia a finales de siglo. Trad. Alfredo Brotons Muñoz. Ed. Akal. España.

[2] Guasch, A. M. (2002): El arte último del siglo XX. Del postmodernismo a lo multicultural. Ed. Alianza Forma. España.

[3] Raine, C. (12 de agosto, 2006). The body beautiful. The Guardian. Recuperado http://www.guardian.co.uk/artanddesign/2006/aug/12/art.edinburgh200 6

Figura 2. Mueck, Ron. Mother and child, 2001. Resina de poliéster pigmentada sobre fibra de vidrio. $24 \times 89 \times 38$ $\mathrm{cm}$. Galería Nacional de Australia.

Ya en la obra de Hanson, aparece una crítica implícita a las sociedades moldeadas por los mass media, en donde el ciudadano promedio estadounidense se mira reflejado. La imagen que ve el espectador de sí mismo o del grueso de su población en las esculturas de Hanson es motivo de una sorpresa inusitada para el espectador actual, más aún para el espectador de esa década. En la obra de Mueck hay elementos adicionales, el uso del silicón, resina de poliéster y fibra de vidrio, además del uso de cabello y vello real en la composición de sus esculturas realza el efecto hiperrealista y la impresión de choque en el espectador. El resultado de su trabajo confirma aquello que en las primeras manifestaciones hiperrealistas ya se mostraba, la frialdad y la desolación de la pura apariencia, del vacío subyacente en la contemplación de la pura imagen carente de significado ulterior: eso es pues el hiperrealismo escultórico de Ron Mueck. 